Technical note

\title{
tracheideR-An R package to standardize tracheidograms
}

\author{
Filipe Campelo*, Cristina Nabais, Ana Carvalho, Joana Vieira \\ Centre for Functional Ecology, Department of Life Sciences, University of Coimbra, Calçada Martim de Freitas, 3000-456 Coimbra, Portugal
}

\section{A R T I C L E I N F O}

\section{Article history:}

Received 13 April 2015

Received in revised form

20 November 2015

Accepted 10 December 2015

Available online 21 December 2015

\section{Keywords:}

Tracheids

Standardization

Density profile

Wood density

Intra-annual density fluctuations

\begin{abstract}
A B S T R A C T
Here we present the package tracheideR to standardize profiles of tracheid features, using the $\mathrm{R}$ computing environment. This package contains a collection of functions to transform the raw data obtained from image analysis into a tracheidogram to better visualize the radial intra-ring variation of histometric parameters. This procedure is crucial when estimating past weather conditions with a sub-annual resolution, since tracheidograms reflect the influence of fluctuations in weather conditions throughout the growing season (such as temperature and soil water content). The main function of this package is tracheider, which takes as input raw tracheidograms and standardizes them using three different methods. The first method standardizes the number of tracheids from different radial files to the mean number of cells, allowing that different annual rings have different number of cells. The second method normalizes the number of cells of different annual rings to the same number. Finally we present a new method to standardize histometric parameters considering the relative position of the cells within the tree ring. This package was tested using two rings of Pinus pinaster to demonstrate variations between the three methods. According to our results species with high intra- and inter-annual variability, as shown by conifers species growing under Mediterranean climate, should be standardized using the "relative position" method. Finally, we suggest that this new method should be applied to other species to check its potential to detect intra-ring fluctuations in tracheid features and to improve our capacity to detect intra-annual climatic signals.
\end{abstract}

(ㄷ) 2015 Elsevier GmbH. All rights reserved.

\section{Introduction}

Tree rings are one of the most reliable natural archive of past climate, being traditionally used as a proxy for climate reconstructions (Briffa et al., 2004; Büntgen et al., 2009; Esper et al., 2002). Tree-ring width has an annual resolution although xylem formation occurs continuously during the growing season (Vieira et al., 2014a). Thus most of the climatic information stored in xylem cells is lost when tree-ring analysis is restricted to ring-width variables. Recently, a growing interest in intra-ring anatomical features has emerged due to the technological and methodological advances in quantitative wood anatomy (Rossi et al., 2006; Gärtner et al., 2014, 2015; von Arx and Carrer, 2014). Studies of intra-ring anatomical features allow a finer resolution of the climatic signal present in tree rings, improving our understanding of the relationship between climate and tree growth (Campelo et al., 2015; De Micco et al., 2014; Vieira et al., 2010). Such studies include monitoring the formation of tree-rings by following the xylogenesis throughout the

\footnotetext{
* Corresponding author.

E-mail address: fcampelo@ci.uc.pt (F. Campelo).
}

growing season and the study of vessels and tracheids properties retrospectively (Carvalho et al., 2015; Vieira et al., 2015). Studies on vessel features, such as lumen area or vessel number, have proven to improve the extraction of climatic signals from tree rings of hardwood species (Campelo et al., 2010; García-González and Fonti, 2006). In conifers, the study of tracheids properties may be achieved by studying the frequency of intra-ring features such as intra-annual density fluctuations (IADFs) or false rings (Campelo et al., 2013, 2007; De Luis et al., 2007; Rozas et al., 2011; Vieira et al., 2010) or by tracheidogram studies (Carvalho et al., 2015; DeSoto et al., 2011; Fonti et al., 2013; Olano et al., 2012), which consists in analyzing the histometric parameters of tracheids over the entire ring (Vaganov, 1990). In the last years studies using tracheidograms have thrive due to the development of new image and data analysis methods (Fonti et al., 2013; von Arx and Carrer, 2014). However there are still several problems regarding the correct standardization of tracheidograms to make them comparable among different trees and years (De Micco et al., 2012; Gartner et al., 2002).

One of the most recognized methods to standardize tracheidograms is the one proposed by Vaganov (1990). This method involves normalizing the number of cells of different years to a constant number. Although this method is reliable for environ- 
A

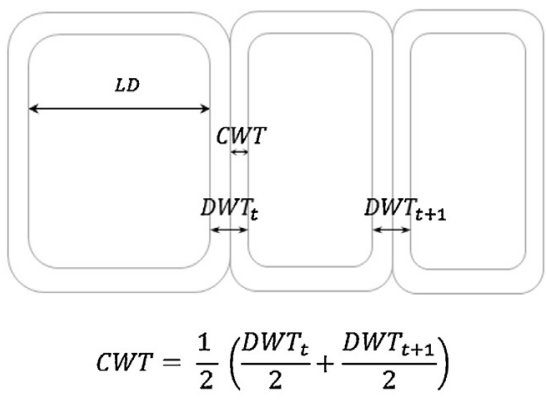

B

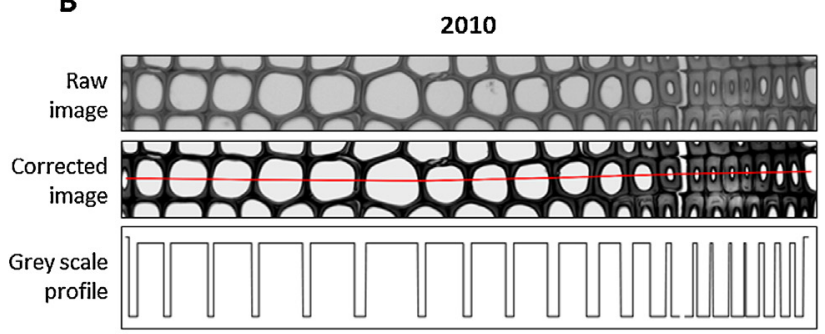

C

2013

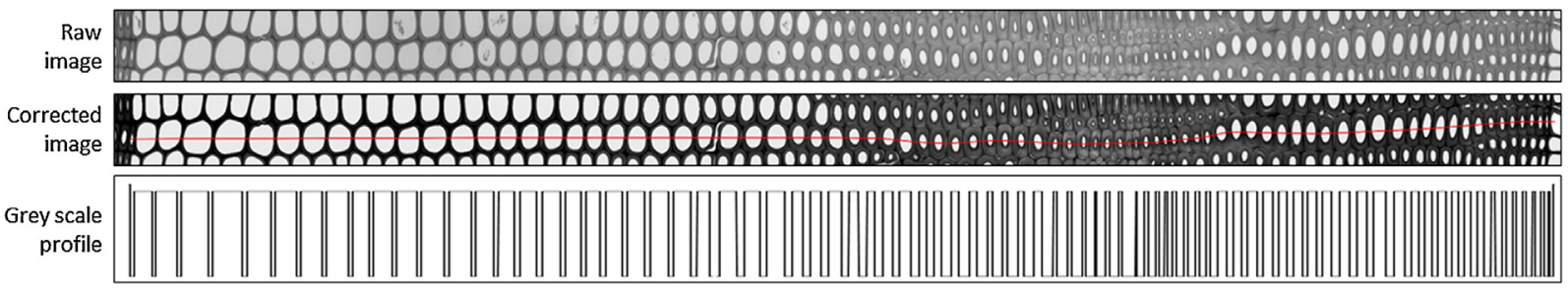

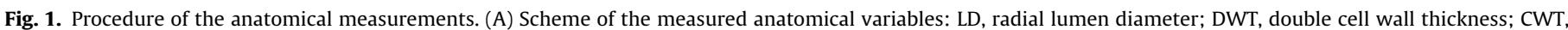

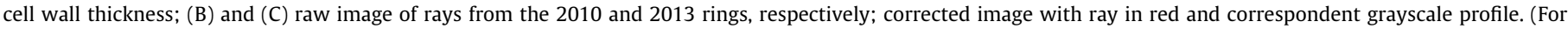
interpretation of the references to color in this figure legend, the reader is referred to the web version of this article.)

ments with little variation in tracheid production between years, in other environments where there is high year-to-year variability, such as the Mediterranean, this method underestimates the variability observed and significant climatic signals might be lost during the standardization process. For example, DeSoto et al. (2011) standardized tracheidograms of Juniperus thurifera L. using an adapted version of the Vaganov method where they selected the average number of earlywood and latewood tracheids of the studied tree rings, which was 20 and 3 respectively. However, in species with high variation in the number of tracheids, such as Pinus pinaster Ait., where there can be differences higher than 20 tracheids between consecutive years (Carvalho et al., 2015; Vieira et al., 2015), this approach cannot be applied. Moreover, this method is unable to determine the relative proportion of IADFs, which are common in conifer species growing in the Mediterranean region (Campelo et al., 2015; De Luis et al., 2011; De Micco et al., 2007). Thus, a new method of standardization is necessary. Here we present a new method where tracheidograms are standardized based on the relative position (relPos) of each tracheid within the ring and compare it with the two previous methods, in order to demonstrate the importance of the standardization method. In the first method the average number of tracheids observed in each year is used to standardize the tracheidograms (nCells), and in the second one a constant number of cells is used (kCells).

\section{Material and methods}

Two rings of $P$. pinaster with distinct growth patterns were selected to illustrate the differences between the methods (Fig. 1). One ring is small without density fluctuations, whereas the other ring is wider and shows a latewood IADF. Microsections of the two rings were analyzed under a light microscope under $200 \times$ magnification and images captured using a digital camera fixed on a microscope (image resolution: $0.169 \mu \mathrm{m} /$ pixel). The freeware program ImageJ was used to analyze tracheid features on digital images (Rasband 1997-2015). First, for each ring three rays were selected and the "plot profile" function applied to obtain a vector of gray values (0-255) along each radial tracheid file (Fig. 1). For each ray, the radial lumen diameter (LD), the radial cell wall thickness (CWT), the ratio of radial lumen diameter to radial cell wall thickness (LD/CWT) and the number of tracheids ( $n$ ) (Fig. $1 \mathrm{~A}$ ) were calculated using the getTrac function, an adapted version of the function tgram from the R package "tgram" (DeSoto et al., 2011). The function tracheider in the R package "tracheideR" was used to obtain standardize tracheidograms using three different methods:

- variable number of cells (nCells): this method standardizes different rays of a given ring using the mean number of cells, allowing that different rings show different number of cells;

Table 1

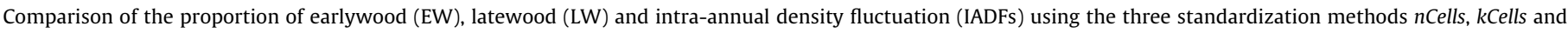
relPos. $n$ and $k$ are the number of tracheids used in each standardization method.

\begin{tabular}{|c|c|c|c|c|c|c|c|c|c|c|c|c|}
\hline & & \multicolumn{11}{|c|}{ Standardization method } \\
\hline & & \multicolumn{4}{|c|}{ nCells } & \multicolumn{4}{|c|}{ kCells } & \multicolumn{3}{|l|}{ relPos } \\
\hline & & $n$ & EW (\%) & LW (\%) & IADF (\% of LW) & $k$ & EW (\%) & $\operatorname{LW}(\%)$ & $\operatorname{IADF}(\%$ of LW) & $\mathrm{EW}(\%)$ & LW (\%) & IADF (\% of LW) \\
\hline \multirow[t]{4}{*}{2010} & ray1 & 22 & $12(54.55)$ & $10(45.45)$ & - & 53 & $30(56.60)$ & $23(43.40)$ & - & 72 & 28 & - \\
\hline & ray 2 & 20 & $12(60.00)$ & $8(40.00)$ & - & 53 & $31(58.49)$ & $22(41.51)$ & - & 77 & 23 & - \\
\hline & ray3 & 19 & $12(63.16)$ & $7(36.84)$ & $1(14.29)$ & 53 & $33(62.26)$ & $20(37.74)$ & $2(10.00)$ & 77 & 23 & $3(13.04)$ \\
\hline & mean & 20 & $12(60.00)$ & $8(40.00)$ & - & 53 & $32(60.38)$ & $21(39.62)$ & - & 76 & 24 & - \\
\hline \multirow[t]{4}{*}{2013} & ray1 & 89 & $37(41.57)$ & $52(58.43)$ & $17(32.69)$ & 53 & $22(41.51)$ & $31(58.49)$ & $10(32.26)$ & 53 & 47 & $19(40.43)$ \\
\hline & ray2 & 82 & 35 (42.68) & $47(57.32)$ & $18(38.30)$ & 53 & $23(43.40)$ & $30(56.60)$ & $11(36.67)$ & 56 & 44 & $19(43.18)$ \\
\hline & ray3 & 85 & $38(44.71)$ & 47 (55.29) & $24(51.06)$ & 53 & $27(50.94)$ & $26(49.06)$ & $13(50.00)$ & 63 & 37 & $19(51.35)$ \\
\hline & mean & 85 & $37(43.53)$ & $48(56.47)$ & $19(39.58)$ & 53 & $23(43.40)$ & $30(56.60)$ & $12(40.00)$ & 55 & 45 & $19(42.22)$ \\
\hline
\end{tabular}


- fixed number of cells $(k C e l l s)$ : this corresponds to the normalized tracheidogram as described by Vaganov (1990), where all rings show the same number of tracheids $(k=53)$;

- relative position within the ring (relPos): this method of standardization determines the relative position of all tracheids by dividing the distance between the start of the ring and the center of each tracheid by the total ring width and multiply by 100 .

The pattern of tracheid features in rings with and without IADFs was compared using the three methods and the intra-ring variation of tracheid features plotted against an environmental variable (soil water content) using the function ringPlot.

\section{Package availability and functionality}

The package tracheideR is available as an add-on package that can be downloaded from the Comprehensive R Archive Network website (CRAN: http://cran.r-project.org). To install tracheideR package, start R console and enter the following commands:

>install.packages ("tracheideR")

$>$ library (tracheideR)

To illustrate the functionality of the tracheideR functions a dataset named "tch" is included in the package. This dataset has 2 years (2010 and 2013) each one with 3 raw profiles (in grayscale) obtained by the "plot profile" function in imageJ, after the manual correction of the original image. An example code is shown here to illustrate how the tracheider function works after computing tracheidograms for a single year (2010) using the getTrac function:

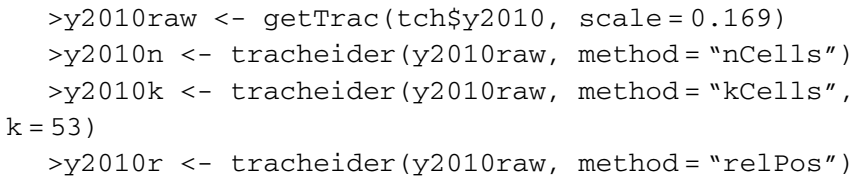

The object y2010raw is then used as input for the tracheider function, where the input argument method can be " $n$ Cells", "kCells" or "relPos". In case of selection of the method "kCells" an additional argument $\mathrm{k}$ should be defined to give the number of tracheids. The intra-ring variation of a tracheid feature (e.g., LD or CWT) can be plotted along the growing season using the ringPlot function. In addition, an environmental variation (e.g., monthly temperature or soil water content) could be added to the same plot to allow a visual comparison of the histometric and environmental variables. The ringPlot works in the following way:

>ringPlot (traq =y2010n, varYear $=\operatorname{sw}[" 2010 "$,$] ,$ type $={ }^{\prime} L D^{\prime}$,

$\mathrm{m} 0=3, \mathrm{mt}=6.75, \mathrm{~m} 1=11$ ) where $\mathrm{y} 2010 \mathrm{n}$ is the tracheidogram for the year 2010 obtained using the tracheider function with the method "nCells", sw ["2010", ] is the monthly values of soil moisture in 2010, the start and the end of the growing season (in months) is given by $\mathrm{m} 0$ and $\mathrm{m} 1$, and $\mathrm{mt}$ is the start of latewood formation.

\section{Results and discussion}

The selected rings presented differences in the number and anatomy of the tracheids formed (Fig. 1B and C and Table 1). In 2010 the ring had only 20 tracheids ( 12 earlywood and 8 latewood) with a clear transition from earlywood to latewood (Fig. 1 B), whereas in 2013 there were 85 tracheids ( 37 earlywood and 48 latewood; Fig. 1C). Although there was also a clear transition between earlywood and latewood in 2013, there was also the formation of an IADF in the end of latewood (Fig. 1C). We selected two years with evident anatomical differences to illustrate the variability of tree
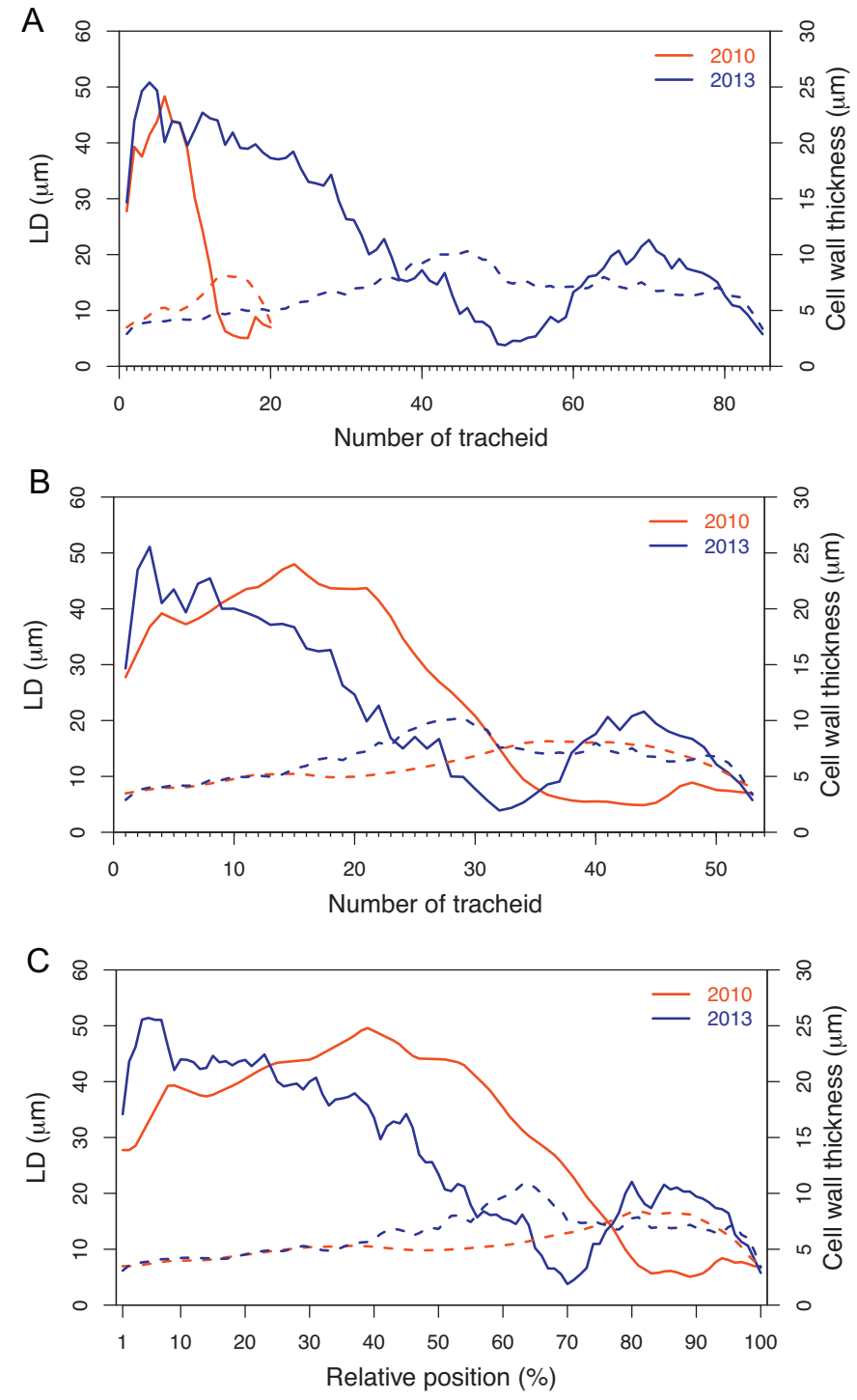

Fig. 2. Standardization of lumen diameter (full line) and cell wall thickness (dash line) of the 2010 (red line) and 2013 (blue line) tracheidograms using the $n$ Cells (A), $k$ Cells (B) and relPos (C) methods. (For interpretation of the references to color in this figure legend, the reader is referred to the web version of this article.)

rings of Mediterranean conifers and to demonstrate the strengths and weaknesses of each standardization method.

The results from the standardization methods presented remarkable differences between them, which are summarized in Table 1 . Both $n$ Cells and $k$ Cells methods overestimated the percentage of latewood, estimating that approximately half of the ring was latewood. The overestimation of latewood came from the fact that only the number of cells was considered without considering differences in cell size. This can represent a drawback in accurately estimating the amount of latewood when tracheid features show a high intra-ring variation (e.g., IADF) and a high inter-ring variability in the number of tracheids. In those cases, applying the relPos method gives a more precise estimation of latewood percentage than the other two methods.

In Fig. 2 the LD and CWT are depicted using the three methods: $n$ Cells (Fig. 2A), kCells (Fig. 2B) and relPos (Fig. 2C). From these graphics, it is possible to see an overestimation of latewood in $n$ Cells and $k$ Cells method. Indeed, these two methods overestimate the relative amount of latewood since they consider that all tracheids have the same size. This was particularly evident when using the 


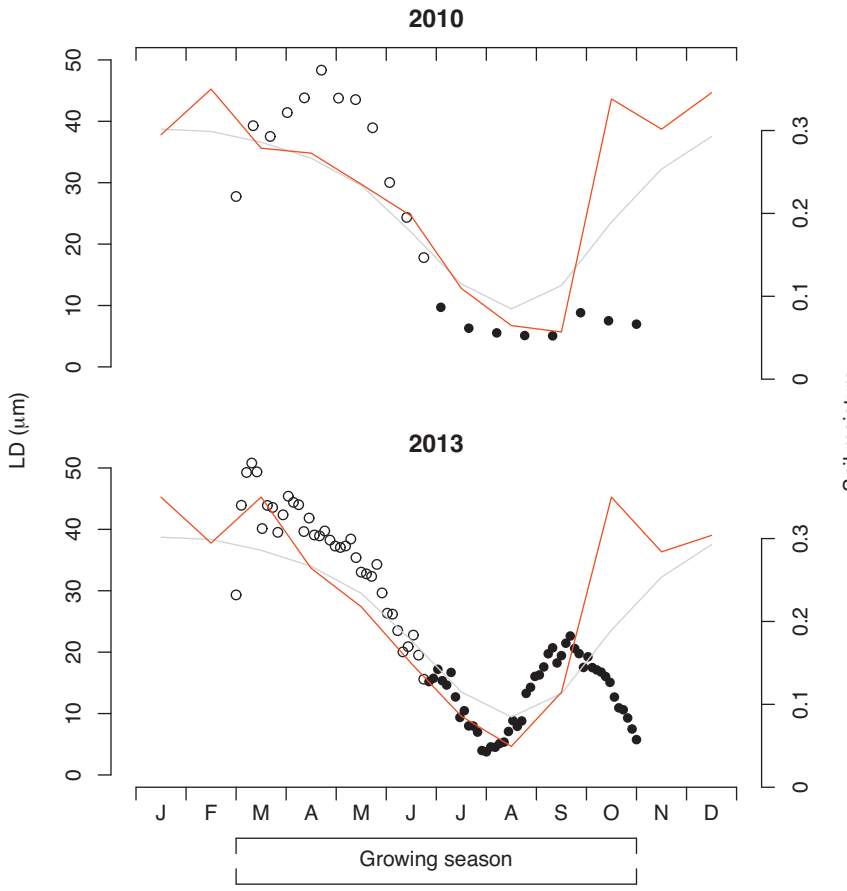

Fig. 3. Relationship between the lumen diameter (LD) of the standardized tracheidograms using the $n$ Cells method and water balance for each year. Red line indicates soil moisture for each studied year; gray line indicates the average soil moisture for the last 30 years; open and solid dots indicate earlywood and latewood tracheids, respectively. (For interpretation of the references to color in this figure legend, the reader is referred to the web version of this article.)

nCells method which overestimated the latewood proportion when compared to relPos method and underestimated the percentage of latewood occupied by the IADF. In environments with smaller variability between years and with shorter growing seasons the $n$ Cells and kCells methods should present reliable results, however in regions with a longer growing season and higher year-to-year climatic variability the relative position of the tracheid within the ring needs to be taken into consideration. It is important to have an accurate estimation of the latewood and earlywood proportion in tree rings due to the physiological implications. Earlywood is mostly responsible for water transport in trees, whereas latewood has a mechanical function and the ratio between the two is highly related to wood density (Domec and Gartner, 2002). An accurate estimation of the volume of wood occupied by earlywood, latewood and IADFs is crucial to precisely determine wood density, productivity and carbon sequestration.

In Figs. 3 and 4 we plotted the intra-ring variation of lumen diameter and cell wall thickness with soil moisture using the function ringPlot. This function can be useful to compare the seasonal variation of an environmental variable and the intra-ring pattern of tracheid features and also to determine the soil water content below which latewood formation starts in different environments and soil types. In the example presented here, we selected a maritime pine plantation on sand dunes. Another feature included in the ringPlot function is the addition of a time component by allowing the user to select the dates of onset and end of wood formation and the date when latewood formation starts. In the examples presented in Figs. 3 and 4 the function was calibrated using the results from cambial activity and wood formation monitoring studies that have been carried out in this site since 2010 (Vieira et al., 2014a,b, 2015). According to these studies the growing season starts in the beginning of March and lasts until the end of October. The start and end of the growing season was defined by the presence or absence of enlarging cells, respectively. The tran-

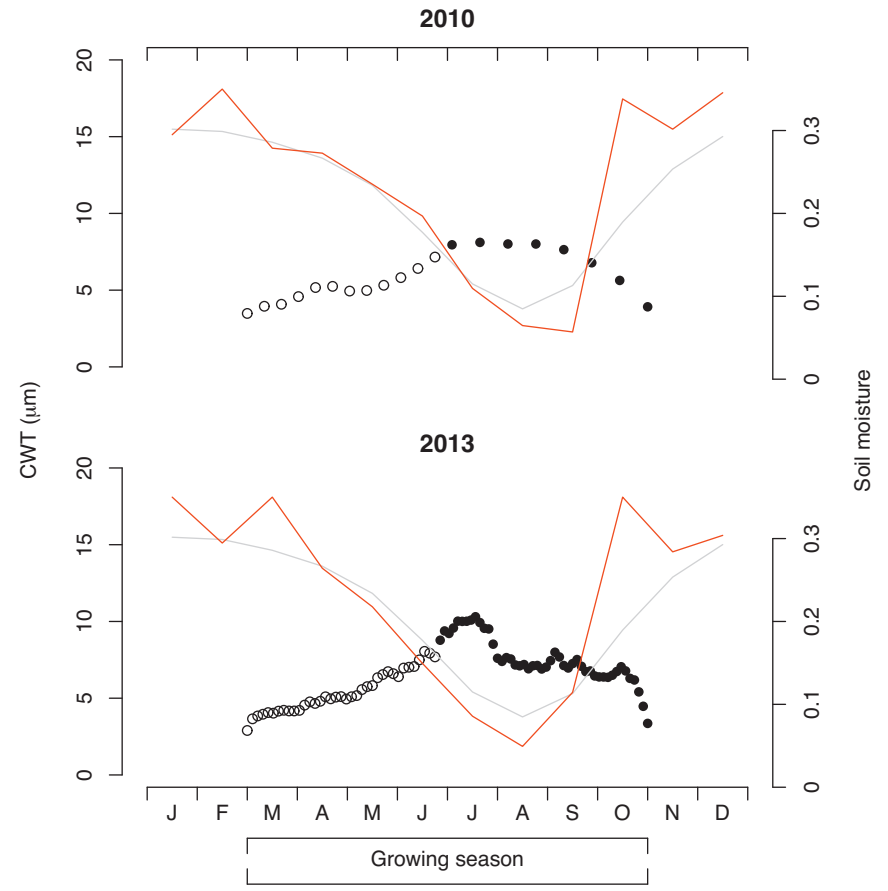

Fig. 4. Relationship between the cell wall thickness (CWT) of the standardized tracheidograms using the nCells method and water balance for each year. Red line indicates soil moisture for each studied year; gray line indicates the average soil moisture for the last 30 years; open and solid dots indicate earlywood and latewood tracheids, respectively. (For interpretation of the references to color in this figure legend, the reader is referred to the web version of this article.)

sition from earlywood to latewood was set to the middle of June, when the soil water content starts to decrease.

Our results clearly demonstrated that in the case of high variation in the number of tracheids the new standardization method produced the best results since it allowed the comparison of rings with different tracheid production while keeping the intraring information. Our method can also be useful when comparing trees growing in different environments. Finally, the relPos method allowed us to better estimate tree productivity and the tree's carbon sequestration capacity.

\section{Acknowledgments}

This study was supported by the Fundação para a Ciência e a Tecnologia, Ministério da Educação e Ciência (FCT) co-financed by Compete, through the project EXPL/AAG-GLO/1885/2013. Filipe Campelo was supported by a postdoctoral research grant (SFRH/BPD/47822/2008), from FCT with funds from POPH (Portuguese Operational Human Potential Program) and QREN Portugal (Portuguese National Strategic Reference Framework). This research also benefited from the support of the FPS COST Action STReESS (FP1106).

\section{References}

Briffa, K., Osborn, T.J., Schweingruber, F.H., 2004. Large-scale temperature inferences from tree rings: a review. Glob. Planet. Change 40, 11-26.

Büntgen, U., Frank, D., Trouet, V., Esper, J., 2009. Diverse climate sensitivity of Mediterranean tree-ring width and density. Trees 24, 261-273.

Campelo, F., Nabais, C., Freitas, H., Gutiérrez, E., 2007. Climatic significance of tree-ring width and intra-annual density fluctuations in Pinus pinea from a dry Mediterranean area in Portugal. Ann. For. Sci. 64, 229-238.

Campelo, F., Nabais, C., Gutiérrez, E., Freitas, H., García-González, I., 2010. Vessel features of Quercus ilex L. growing under Mediterranean climate have a better climatic signal than tree-ring width. Trees 24, 463-470. 
Campelo, F., Vieira, J., Battipaglia, G., de Luis, M., Nabais, C., Freitas, H., Cherubini, P., 2015. Which matters most for the formation of intra-annual density fluctuations in Pinus pinaster: age or size? Trees 29, 237-245.

Campelo, F., Vieira, J., Nabais, C., 2013. Tree-ring growth and intra-annual density fluctuations of Pinus pinaster responses to climate: does size matter? Trees 27 763-772.

Carvalho, A., Nabais, C., Vieira, J., Rossi, S., Campelo, F., 2015. Plastic response of tracheids in Pinus pinaster in a water-limited environment: adjusting lumen size instead of wall thickness. PLoS One 10, e0136305.

De Luis, M., Gričar, J., Čufar, K., Raventós, J., 2007. Seasonal dynamics of wood formation in Pinus halepensis from dry and semi-arid ecosystems in Spain. IAWA J. 28, 389-404.

De Luis, M., Novak, K., Raventós, J., Gričar, J., Prislan, P., Čufar, K., 2011. Climate factors promoting intra-annual density fluctuations in Aleppo pine (Pinus halepensis) from semiarid sites. Dendrochronologia 29, 163-169.

De Micco, V., Saurer, M., Aronne, G., Tognetti, R., Cherubini, P., 2007. Variations of wood anatomy and $\delta^{13} \mathrm{C}$ within-tree rings of coastal Pinus pinaster showing intra-annual density fluctuations. IAWA J. 28, 61-74.

De Micco, V., Battipaglia, G., Brand, W., 2012. Discrete versus continuous analysis of anatomical and $\delta^{13} \mathrm{C}$ variability in tree rings with intra-annual density fluctuations. Trees, 513-524.

De Micco, V., Battipaglia, G., Cherubini, P., Aronne, G., 2014. Comparing methods to analyse anatomical features of tree rings with and without intra-annual density fluctuations (IADFs). Dendrochronologia 32, 1-6.

DeSoto, L., de la Cruz, M., Fonti, P., 2011. Intra-annual patterns of tracheid size in the Mediterranean tree Juniperus thurifera as an indicator of seasonal water stress. Can. J. For. Res. 41, 1280-1294.

Domec, J.-C., Gartner, B.L., 2002. How do water transport and water storage differ in coniferous earlywood and latewood? J. Exp. Bot. 53, 2369-2379.

Esper, J., Schweingruber, F.H., Winiger, M., 2002. 1300 years of climatic history for Western Central Asia inferred from tree-rings. Holocene 12, 267-277.

Fonti, P., Bryukhanova, M.V., Myglan, V.S., Kirdyanov, A.V., Naumova, O.V., Vaganov, E.A., 2013. Temperature-induced responses of xylem structure of Larix sibirica (Pinaceae) from Russian Altay. Am. J. Bot. 100, 1-12.

García-González, I., Fonti, P., 2006. Selecting earlywood vessels to maximize their environmental signal. Tree Physiol. 26, 1289-1296.
Gartner, B.L., Aloni, R., Funada, R., Lichtfuss-Gautier, A.N., Roig, F.A., 2002. Clues for dendrochronology from studies of wood structure and function. Dendrochronologia 20, 53-61.

Gärtner, H., Lucchinetti, S., Schweingruber, F.H., 2014. New perspectives for wood anatomical analysis in dendrosciences: the GSL1-microtome.

Dendrochronologia 32, 47-51.
Gärtner, H., Banzer, L., Schneider, L., Schweingruber, F.H., Bast, A., 2015. Preparing micro sections of entire (dry) conifer increment cores for wood anatomical time-series analyses. Dendrochronologia 34, 19-23.

Olano, J.M., Eugenio, M., García-Cervigón, A.I., Folch, M., Rozas, V., 2012. Quantitative tracheid anatomy reveals a complex environmental control of wood structure in continental Mediterranean climate. Int. J. Plant Sci. 173, 137-149.

Rasband, W.S., 1997-2015. ImageJ. U.S. National Institutes of Health, Bethesda, Maryland, USA http://imagej.nih.gov/ij/.

Rossi, S., Anfodillo, T., Menardi, R., 2006. Trephor: a new tool for sampling microcores from tree stems. IAWA J. 27, 89-97.

Rozas, V., García-González, I., Zas, R., 2011. Climatic control of intra-annual wood density fluctuations of Pinus pinaster in NW Spain. Trees 25, 443-453.

Vaganov, E.A., 1990. The tracheidogram method in tree-ring analysis and its application. In: Cook, E., Kairiukstis, L. (Eds.), Methods of Dendrochronology: Applications in the Environmental Sciences. Kluwer Academic Publishers, Dordrecht, The Netherland, pp. 63-76.

Vieira, J., Campelo, F., Nabais, C., 2010. Intra-annual density fluctuations of Pinus pinaster are a record of climatic changes in the western Mediterranean region. Can. J. For. Res. 40, 1567-1575.

Vieira, J., Rossi, S., Campelo, F., Freitas, H., Nabais, C., 2014a. Xylogenesis of Pinus pinaster under a Mediterranean climate. Ann. For. Sci. 71, 71-80.

Vieira, J., Rossi, S., Campelo, F., Nabais, C., 2014b. Are neighboring trees in tune? Wood formation in Pinus pinaster. Eur. J. For. Res. 133, 41-50.

Vieira, J., Campelo, F., Rossi, S., Carvalho, A., Freitas, H., Nabais, C., 2015. Adjustment capacity of maritime pine cambial activity in drought-prone environments. PLoS One 10, e0126223.

von Arx, G., Carrer, M., 2014. ROXAS-a new tool to build centuries-long tracheid-lumen chronologies in conifers. Dendrochronologia 32, 290-293. 